\title{
Nutritional Intake by Meal Time Zone in Geriatric Patients Is Related to Nutritional Assessment Index
}

\author{
Yasuko Fukuda a, b, e, Ryouko Kanazawa ${ }^{\mathrm{a}}$, Narumi Yao ${ }^{\mathrm{a}}$, Tomoka Ishida ${ }^{\mathrm{a}}$, Asuka Nakaoka ${ }^{\mathrm{a}}$, \\ Momoko Tazuhara ${ }^{a}$, Sayaka Yao ${ }^{a}$, Saki Nakatani ${ }^{a}$, Hiromu Nakajima ${ }^{c}$, \\ Masanobu Nakai ${ }^{\mathrm{d}}$
}

\begin{abstract}
Background: The blood metabolome profiles depend on the meal intake time zone regardless of having the same meal. The serum albumin (Alb) level, which is important in managing geriatric patients with chronic diseases, is included in the metabolome analysis. In this study, we aimed to examine the relationship between Alb and the nutritional value of hospital meals consumed at breakfast, lunch, and dinner among geriatric patients. Chrononutrition was considered while drawing inferences.

Methods: We retrospectively surveyed 52 geriatric patients with chronic diseases (aged $79.7 \pm 8.7$ years) admitted at a small-scale hospital providing combined healthcare measures and oral nutritional support. The dietary intake per kilogram of body weight of nutritional components for breakfast, lunch, and dinner was individually expressed as the ratio to the whole daily food intake. The dietary pattern was determined by principal component analysis. We also conducted linear regression analysis, with Alb as the dependent variable, and age, sex, and grade assigned in this study as well as the first, second, and third principal components of the dietary patterns as the independent variables.
\end{abstract}

Results: Three principal components with an eigenvalue of $>1$ were extracted. The second principal component was a significantly negative determinant factor for $\mathrm{Alb}(\mathrm{B}=-0.108, \mathrm{P}=0.016)$. In patients with high Alb levels, the energy, protein, and fat ratios at lunch were

Manuscript submitted May 16, 2021, accepted June 7, 2021

Published online June 25, 2021

aDepartment of Food Science and Nutrition, School of Human Environmental Science, Mukogawa Women's University, Ikebiraki-cho, Nishinomiya, Hyogo 663-8558, Japan

bResearch Institute for Nutrition Science, Mukogawa Women's University, Ikebiraki-cho, Nishinomiya, Hyogo 663-8558, Japan

'Department of Endocrinology and Metabolism/Clinical Laboratory, Osaka International Cancer Institute, Chuo-ku, Osaka 541-8567, Japan

dNakai Hospital, Nada-ku, Kobe, Hyogo 657-0833, Japan

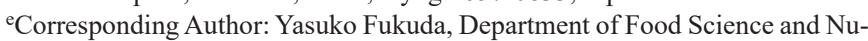
trition, School of Human Environmental Science, Mukogawa Women's University, Ikebiraki-cho, Nishinomiya, Hyogo 663-8558, Japan.

Email: yafukuda@mukogawa-u.ac.jp

doi: https://doi.org/10.14740/jocmr4524 positively correlated, while the energy and carbohydrate ratios at dinner were negatively correlated. Mealtimes were fixed.

Conclusions: The results of this study showed that the dietary pattern predominantly observed in patients with high Alb levels may be positively associated with Alb synthesis.

Keywords: Dietary pattern; Geriatric patient; Principal component analysis; Serum albumin; Meal time zone

\section{Introduction}

In our modern society, the consumption timing of daily required dietary and nutritional intake that can benefit the health of geriatric patients with chronic diseases has gained increasing attention. When considering sarcopenia and frailty prevention, the nutritional status should be determined by identifying the indices that are deeply related to nutritional and physical strengths. Chrononutrition aims to elucidate the differences in the effective timings of dietary and nutrition intake for health maintenance and improvement by considering the fluctuations in physiological functions controlled by the biological clock [1].

Serum albumin (Alb) is a protein produced only in the liver. It reflects the nutritional status of the whole body and is a good index of undernutrition. Thus, Alb has become one of the important nutritional assessment indices in the nutrition support team $[2,3]$.

Our local small-scale hospital, which provides combined healthcare measures, caters continuous treatment and rehabilitation to geriatric patients, who have completed their acute-phase treatment, and are either awaiting admission to nursing facilities or discharge support receive. In such cases, registered dietitians should provide appropriate nutritional support by determining the patients' nutritional intake for breakfast, lunch, and dinner. Selection of the discharge destination of geriatric patients is influenced by their nonprotein caloric/nitrogen (NPC/N) intake after hospital meal consumption [4].

Hence, this study aimed to improve the factors influencing $\mathrm{Alb}$ in geriatric nutritional management and analyze the effects of dietary nutritional composition and meal timing. 


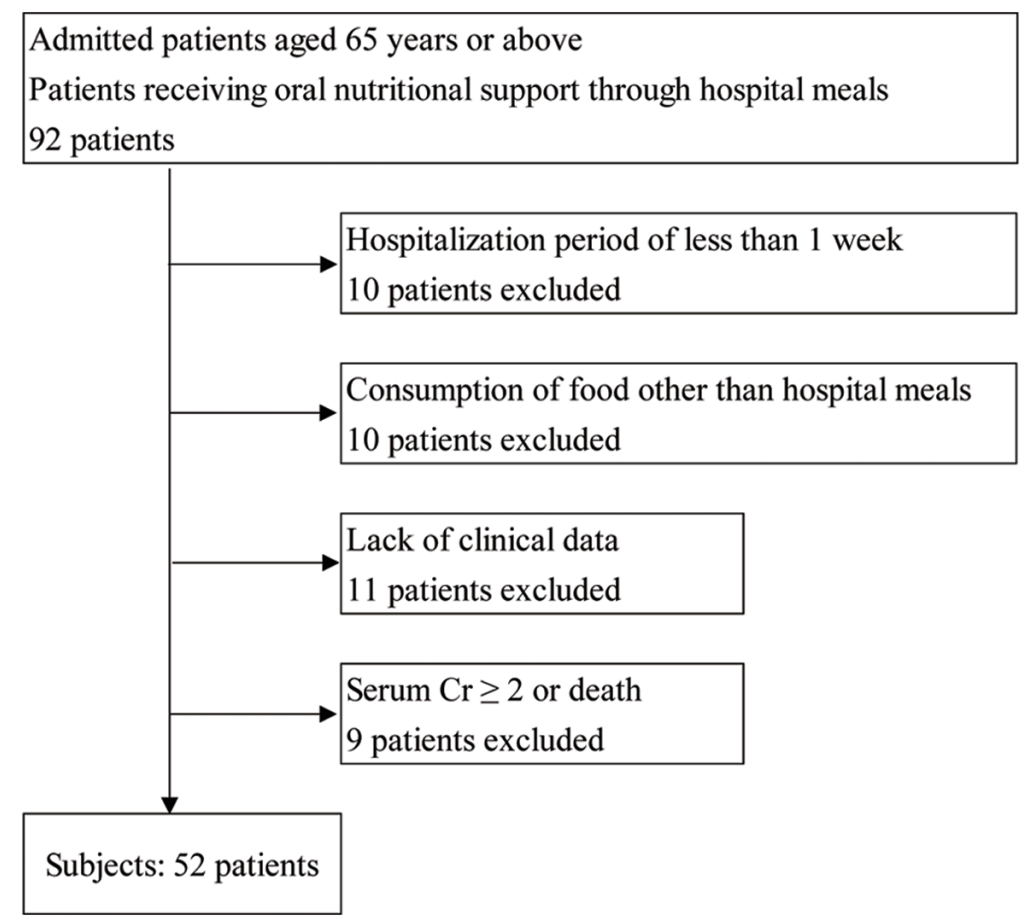

Figure 1. Scheme for subject recruitment and study workflow. Cr: creatinine.

\section{Materials and Methods}

\section{Subjects}

Between April 2019 and July 2020, this study enrolled 52 geriatric patients $(79.7 \pm 8.7$ years; 33 males, 19 females $)$ who appeared in our previous study [4] and were admitted at a small-scale (48-bed capacity) hospital that provides combined healthcare measures, in Nada Ward, Kobe City in Hyogo Prefecture. These patients, who had fixed dietary and living times and were under oral nutritional support, responded to our selfadministered survey.

Figure 1 illustrates the flow diagram of subject recruitment and study workflow. No double counting transpired. We excluded patients with severe protein intake restrictions $(\leq 45$ $\mathrm{g} /$ day) and those with a C-reactive protein of $\geq 2 \mathrm{mg} / \mathrm{dL}$. In addition, no patient exhibited protein-losing gastroenteropathy.

Furthermore, we extracted the following survey items from the medical records: basic attributes during hospitalization, comorbidities, body mass index, serum albumin level (Alb), blood biochemical data, nursing care level, hospitalization duration, and intake types at each meal/side dish 4 weeks after hospitalization.
Comorbidities were scored according to the Charlson Comorbidity Index [5]. For the nursing care level, we used the standard recognized by the long-term care insurance system [6]; those patients requiring assistance of 1 - 2 were assigned to numbers $1-2$, while those requiring nursing care of $1-5$ were assigned to numbers 3 - 7 (Table 1). Hospitalization duration was the number of days from hospital admission to discharge.

With the patient in the supine position, fasting blood samples were collected in the morning.

\section{Extraction of dietary patterns}

The hospital meal intake status was structurally determined by 12 variables, which were regarded as dietary patterns in principal component analysis. The principal component extraction standard was an eigenvalue of $\geq 1$, and the factor loading for the food groups representing the principal components was set at $\geq 0.30$.

The dietary intake per kilogram of body weight (BW) for breakfast, lunch, and dinner nutritional components was individually expressed as a ratio of the 12 variables to total daily food intake. Thus, cases were adjusted for the variety of hospital meals, which were based on the subject's preference and/

Table 1. Numerical Notations of Nursing Care Level

\begin{tabular}{|c|c|c|c|c|c|c|c|}
\hline \multirow{2}{*}{$\begin{array}{l}\text { Grade defined by the long- } \\
\text { term care insurance act }\end{array}$} & \multicolumn{7}{|c|}{ Mild $\leftarrow$ Breakdown $\rightarrow$ Severe } \\
\hline & $\begin{array}{l}\text { Assistance } \\
\text { required } 1\end{array}$ & $\begin{array}{l}\text { Assistance } \\
\text { required } 2\end{array}$ & $\begin{array}{l}\text { Nursing care } \\
\text { required } 1\end{array}$ & $\begin{array}{l}\text { Nursing care } \\
\text { required } 2\end{array}$ & $\begin{array}{l}\text { Nursing care } \\
\text { required } 3\end{array}$ & $\begin{array}{l}\text { Nursing care } \\
\text { required } 4\end{array}$ & $\begin{array}{l}\text { Nursing care } \\
\text { required } 5\end{array}$ \\
\hline
\end{tabular}


or the physician's discretion. The hospital meals consisted of various regular and medical diet recipes, with the staple food ranging from rice to porridge or bread. Below is a sample formula for calculating breakfast energy ratio.

Breakfast energy $(\mathrm{B}$ En) ratio $=($ Breakfast energy intake $(\mathrm{kcal} / \mathrm{BW} \mathrm{kg} /$ day))/(daily total energy intake ( $\mathrm{kcal} / \mathrm{BW} \mathrm{kg} /$ day))

We used the same formula for calculating the following variables: breakfast protein (B Pro), breakfast fat (B Fat), breakfast carbohydrate (B Carb), lunch energy (L En), lunch protein (L Pro), lunch fat (L Fat), lunch carbohydrate (L Carb), dinner energy (D En), dinner protein (D Pro), dinner fat (D Fat), and dinner carbohydrate (D Carb) ratios.

\section{Relationship between dietary patterns and Alb}

The relationship between dietary patterns and Alb was examined by linear regression analysis. Alb was set as the dependent variable, whereas age, sex, and grade assigned in this study as well as first, second, and third principal components were used as the independent variables.

\section{Statistical analysis}

All statistical data were analyzed by Statistical Analysis System (SAS) version 9.4 (SAS Institute Inc., Cary, NC, USA). The significance level was set as $<5 \%$ in the two-sided test.

\section{Ethical considerations}

This study was approved by the Research Ethics Committee of Mukogawa Women's University and Junior College on March 15, 2019 (Approval No. 18-85), and was conducted according to the principles of the Declaration of Helsinki. We obtained the subjects' informed consent, with the assurance that they would remain anonymous and could withdraw from the study anytime.

\section{Results}

\section{Subject demographics}

The main conditions included chronic heart failure, bronchial pneumonia, chronic obstructive pulmonary disease, type 2 diabetes, lumbar compression fracture, hypertension, hyperlipidemia, femoral neck fracture, Parkinson's disease, disuserelated atrophy of the lower-limb muscles, and degenerative lumbar spondylosis. Meanwhile, comorbidities included chronic hepatitis $\mathrm{B}$, chronic hepatitis $\mathrm{C}$, type 2 diabetes, lipid abnormality, gastric ulcer, iron-deficiency anemia, and constipation. The main conditions and comorbidities had been treated at the acute care hospital, and thus the patients' conditions became stable (Table 2).

Mealtimes were 8:00 am (breakfast), 12:00 pm (lunch), and 6:00 pm (dinner), and we cleared the table an hour after meals were served.

Energy intake according to types of meals was $10.3 \pm$ $2.6 \mathrm{kcal} / \mathrm{BW} \mathrm{kg} /$ day (breakfast), $11.5 \pm 3.1 \mathrm{kcal} / \mathrm{BW} \mathrm{kg} /$ day (lunch), and $11.1 \pm 3.0 \mathrm{kcal} / \mathrm{BW} \mathrm{kg} /$ day (dinner), whereas protein intake was $0.3 \pm 0.2 \mathrm{~kg} / \mathrm{BW} \mathrm{kg} /$ day (breakfast), $0.4 \pm 0.1$ $\mathrm{kg} / \mathrm{BW} \mathrm{kg}$ /day (lunch), and $0.5 \pm 0.1 \mathrm{~kg} / \mathrm{BW} \mathrm{kg}$ /day(dinner) (Table 2). No patients met the criteria for excessive or insufficient daily required nutritional intake based on requirements prescribed by the primary physician.

The nutrition quantity of the hospital meals at breakfast, lunch, and dinner was almost evenly distributed (Table 3).

\section{Extraction of dietary patterns}

Three principal components with an eigenvalue of $>1$ were extracted, which accounted for $87.3 \%$ of total variance. Components with a nutrition intake ratio of $\geq 0.30$ were selected as the principal component loadings for interpretation of dietary patterns according to the principal components. Factor loadings of the three principal components are shown in Table 4.

In the first principal component, the L En ratio (0.327) was positively correlated, whereas the B En $(-0.425)$, B Pro $(-0.338)$, B Fat $(-0.323)$, and B Carb $(-0.303)$ ratios were negatively correlated.

In the second principal component, the D En (0.430) and D Carb (0.417) ratios were positively correlated, whereas the L Pro (-0.435), L Fat (-0.343), and L En (-0.327) ratios were negatively correlated.

In the third principal component, the B Carb (0.417), D Pro $(0.394)$, and D Fat $(0.368)$ ratios were positively correlated, whereas the L Carb (-0.432) and B Fat (-0.367) ratios were negatively correlated.

\section{Relationship between dietary patterns and Alb}

The second principal component was a significantly negative determining factor for Alb $(\mathrm{B}=-0.108, \mathrm{P}=0.016$, Table 5). In other words, the dietary pattern of patients with high Alb levels was "characterized by the L En, L Pro, and L Fat ratios showing a positive correlation, and the D En and D Carb ratios showing a negative correlation."

No associations were observed between the first and third principal components and Alb. Furthermore, the first, second, and third principal components were not associated with the geriatric and prognostic nutritional indices and nutritional status control (Supplementary Materials 1-3, www.jocmr.org). Evaluation of whether the scores of the second principal component were associated with age, sex, grade assigned in this study and Alb revealed that they were negatively correlated with Alb $(\rho=-0.399$. P $=0.005$, Supplementary Material 4, www.jocmr.org).

\section{Discussion}

This study demonstrated that with respect to the indicated 
Table 2. Demographics

\begin{tabular}{|c|c|c|}
\hline Number of patients (male/female) & $52(33 / 19)$ & \\
\hline Age (years) & $79.7 \pm 8.7$ & $(75.0-86.0)$ \\
\hline Body mass index $\left(\mathrm{kg} / \mathrm{m}^{2}\right)$ & $21.2 \pm 4.0$ & $(17.8-24.4)$ \\
\hline Duration of hospitalization (days) & $52.6 \pm 36.7$ & $(27.8-64.8)$ \\
\hline Alb (g/dL) & $3.4 \pm 0.5$ & $(3.0-3.8)$ \\
\hline $\mathrm{FPG}(\mathrm{mg} / \mathrm{dL})$ & $101.1 \pm 24.1$ & $(89-106)$ \\
\hline $\mathrm{Cr}(\mathrm{mg} / \mathrm{dL})$ & $1.0 \pm 0.6$ & $(0.67-1.18)$ \\
\hline eGFR $\left(\mathrm{mL} / \mathrm{min} / 1.73 \mathrm{~m}^{2}\right)$ & $60.9 \pm 24.7$ & $(42.4-72.4)$ \\
\hline GNRI (score) & $91.0 \pm 12.5$ & $(84.1-97.9)$ \\
\hline PNI (score) & $41.6 \pm 5.9$ & $(38.7-45.8)$ \\
\hline CONUT (score) & $3.7 \pm 2.2$ & $(2.8-4.5)$ \\
\hline Assistance required $1, \mathrm{n}$ & 1 & \\
\hline Assistance required $2, \mathrm{n}$ & 3 & \\
\hline Nursing care required $1, \mathrm{n}$ & 7 & \\
\hline Nursing care required $2, \mathrm{n}$ & 16 & \\
\hline Nursing care required $3, \mathrm{n}$ & 6 & \\
\hline Nursing care required $4, n$ & 6 & \\
\hline Nursing care required $5, \mathrm{n}$ & 6 & \\
\hline \multicolumn{3}{|l|}{ Nutrient intake } \\
\hline Energy intake (kcal/BW kg/day) & $33.0 \pm 8.4$ & $(26.1-37.2)$ \\
\hline Breakfast (kcal/BW kg/day) & $10.3 \pm 2.6$ & $(8.4-12.4)$ \\
\hline Fat intake (g/BW kg/day) & $0.9 \pm 0.3$ & $(0.7-1.1)$ \\
\hline Breakfast (g/BW kg/day) & $0.3 \pm 0.1$ & $(0.2-0.4)$ \\
\hline Lunch (g/BW kg/day) & $0.3 \pm 0.1$ & $(0.2-0.3)$ \\
\hline Dinner (g/BW kg/day) & $0.3 \pm 0.1$ & $(0.2-0.4)$ \\
\hline Carbohydrate intake (g/BW kg/day) & $5.0 \pm 1.3$ & $(4.0-5.7)$ \\
\hline Breakfast (g/BW kg/day) & $1.5 \pm 0.4$ & $(1.2-1.7)$ \\
\hline Lunch (g/BW kg/day) & $1.8 \pm 0.5$ & $(1.4-2.1)$ \\
\hline Dinner (g/BW kg/day) & $1.7 \pm 0.5$ & $(1.3-2.0)$ \\
\hline $\mathrm{NPC} / \mathrm{N}$ mean & $140.6 \pm 10.6$ & $(135.2-148.3)$ \\
\hline Breakfast & $163.6 \pm 16.1$ & $(150.6-177.2)$ \\
\hline Lunch & $139.1 \pm 16.7$ & $(129.1-152.8)$ \\
\hline Dinner & $126.1 \pm 10.8$ & $(121.4-131.4)$ \\
\hline
\end{tabular}

Data are expressed as mean \pm standard deviation. Inside is quartile. The main diseases for admission included chronic heart failure, bronchial pneumonia, chronic obstructive pulmonary disease, and type 2 diabetes; however, these conditions had been treated in the acute care hospital, and thus, patients' condition became stable. Alb: serum albumin; FPG: fasting plasma glucose; BUN: blood urea nitrogen; Cr: creatinine; eGFR: estimated glomerular filtration rate; BW: body weight. GNRI: geriatric nutritional risk index; PNI: prognostic nutritional index; CONUT: controlling nutritional status; NPC/N: nonprotein caloric/nitrogen. 
Table 3. Nutritional Composition of the Hospital Meal Menu

\begin{tabular}{|c|c|c|c|c|}
\hline & Breakfast & Lunch & Dinner & Mean \\
\hline \multicolumn{5}{|c|}{ Ratio to daily intake of each nutrient (\%) } \\
\hline Energy intake & $31.3 \pm 2.7$ & $34.9 \pm 1.8$ & $33.8 \pm 2.3$ & - \\
\hline Fat intake & $34.5 \pm 5.4$ & $32.2 \pm 4.3$ & $33.3 \pm 4.3$ & - \\
\hline Carbohydrate intake & $30.9 \pm 3.0$ & $36.0 \pm 2.0$ & $33.1 \pm 2.2$ & - \\
\hline \multicolumn{5}{|l|}{ Energy ratio of each nutrient (\%) } \\
\hline Fat/energy ratio & $27.7 \pm 6.0$ & $24.3 \pm 4.7$ & $26.3 \pm 4.2$ & $25.8 \pm 3.7$ \\
\hline Carbohydrate/energy ratio & $59.7 \pm 6.9$ & $59.3 \pm 5.7$ & $56.2 \pm 5.7$ & $58.5 \pm 4.4$ \\
\hline Menu characteristics & $\begin{array}{l}\text { The main staple provided is bread } \\
\text { or porridge, the side dishes provided } \\
\text { are milk, fruits (fresh or canned food/ } \\
\text { jelly) and sides (vegetable dishes). } \\
\text { In addition, bread comes with jam } \\
\text { and butter, and porridge comes with } \\
\text { seaweed/pickled plum paste. }\end{array}$ & \multicolumn{3}{|c|}{$\begin{array}{l}\text { Set menu of rice or porridge as } \\
\text { the main staple, and a main dish } \\
\text { with } 2-3 \text { sides as the side dishes. } \\
\text { Eggs/fish/meat, soy products and } \\
\text { vegetables/fruits are used as the } \\
\text { ingredients. Noodles or special } \\
\text { menu are provided at lunch. }\end{array}$} \\
\hline
\end{tabular}

Data are expressed as mean \pm standard deviation.

quantity, the energy and protein intake of geriatric patients hospitalized at a local small-scale hospital providing combined healthcare measures was not excessive or deficient. The meals were consumed at particular times, and the nutritional compositions were related to Alb. We considered the intake status at breakfast, lunch, and dinner with respect to each nutrient as a dietary pattern and examined its relationship with Alb by linear regression analysis. Results showed that the second principal component had a significantly negative correlation with Alb. Thus, "a dietary pattern characterized by the positively cor-

Table 4. Dietary Pattern

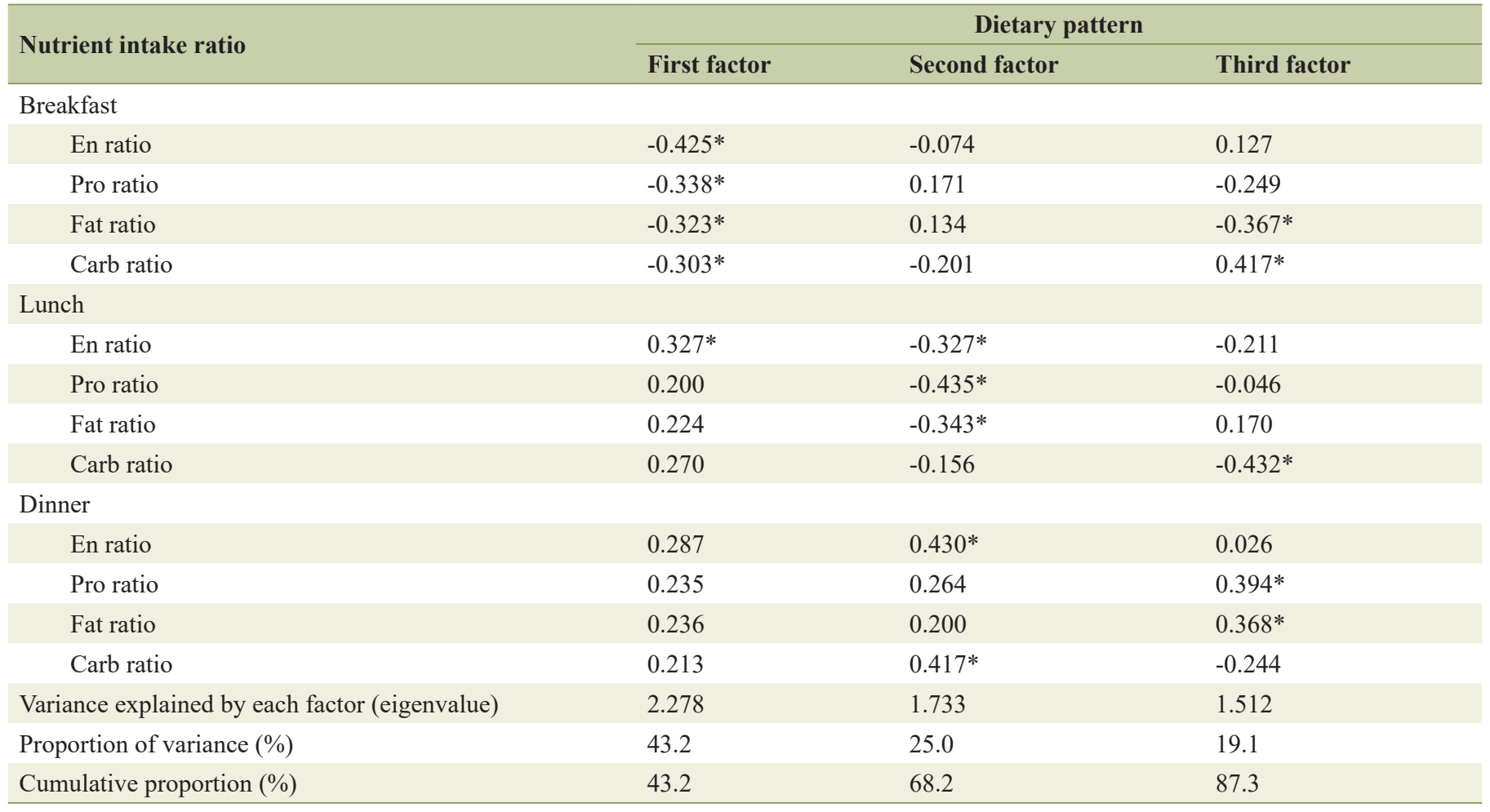

${ }^{*} \mid$ load $\mid>0.300$ were considered as an important factor (in module). En: energy; Pro: protein; Carb: carbohydrate. 
Table 5. Multiple Regression Models of Serum Albumin

\begin{tabular}{lllll} 
& Regression coefficient & Standard error & t value & P value \\
\hline Age & -0.010 & 0.012 & -0.833 & 0.410 \\
Sex & 0.162 & 0.165 & 0.984 & 0.331 \\
Grade assigned in this study & -0.040 & 0.046 & -0.860 & 0.395 \\
First factor & -0.048 & 0.036 & -1.320 & 0.194 \\
Second factor & -0.100 & 0.045 & -2.228 & $0.032 *$ \\
Third factor & -0.014 & 0.051 & -0.274 & 0.786 \\
\hline
\end{tabular}

${ }^{*} P<0.05(n=52)$.

related L En, L Pro, and L Fat ratios and the negatively correlated D En and D Carb ratios" could influence Alb metabolism positively.

In an investigation related to meal timing, Takahashi et al comprehensively compared the metabolic dynamics in blood at breakfast and dinner by using the Human Metabolome Database. Their study results suggested that the metabolic activities of the energy-generating and biological component synthesis systems, especially, glycolysis, tricarboxylic acid cycle (TCA) cycle, and amino acid metabolism, were higher at breakfast than at dinner [7].

In a study on the meal timing of functional food (Jerusalem artichoke powder; water-soluble dietary fiber) in subjects aged $\geq 65$ years, the intake before breakfast more significantly correlated with the reduction of diurnal blood glucose and increase of the intestinal flora than that before dinner [8].

In the present study, the patients with high Alb levels exhibited "a dietary pattern characterized by the L En, L Pro, and L Fat ratios showing a positive correlation and the D En and D Carb ratios showing a negative correlation."

Inflammation, severe liver dysfunction, and protein-losing gastroenteropathy substantially affect Alb levels; however, in this study, no patients experienced these diseases. On the basis of this fact, we thought that the amount of nutritional intake according to meal timing may be associated with Alb synthesis.

As the intake status of hospital meals differs depending on types and conditions of chronic diseases and oral conditions, hospital staff adjusted the hardness of staple foods and types of side dishes. Patients were allowed to maintain a daily required nutritional quantity by consuming several types of hospital foods. They were served three hospital meals a day (i.e., breakfast, lunch, and dinner). However, we thought that the daily required nutritional quantity differed among the patients because of their food preferences. To standardize the nutritional quantity as much as possible, we divided meals into breakfast, lunch, and dinner and then classified nutrients into energy, protein, fat, and carbohydrates. Subsequently, the dietary intake per kilogram of BW was calculated and the resulting value was expressed as the ratio to the whole daily food intake.

No excessive or insufficient nutrient intake was observed in terms of the total nutrient quantity through a simple calculation. This was a reasonable result because the hospital staff considered nutritional balance when they planned pa- tient meals. This enabled homogenous daily nutrient quantity, although there were some variations in the nutrient intake at breakfast, lunch, and dinner.

However, principal component analysis (which was performed to obtain lower-dimensional data while preserving as much of multidimensional characteristics of nutrient quantity for breakfast, lunch, and dinner as possible) revealed a negative correlation between the second principal component and Alb.

In terms of the second principal component, a positive correlation was observed in the following factors in patients with high Alb levels: the energy, protein, and fat ratios at lunch. In contrast, a negative correlation was found in the energy and carbohydrate ratios at dinner.

Given that protein, fat, and carbohydrate are nutrients that produce energy, nutritional compositions in which the energy ratio of protein and fat increases at lunch but that of carbohydrate decreases at dinner within the allowable range may be associated with high Alb levels.

As the age advances, disruption in body clock rhythm worsens. Ando et al analyzed the factors correlating with the expression level of the clock gene messenger RNA (mRNA) in peripheral blood cells in 99 healthy subjects (29 males; average age, 56 years). They found that the factors age, wake-up time, drinking amount, and fasting blood glucose level had a significantly inverse correlation with at least one of the measured clock genes. That is, those who were elderly, who woke up late, who drank heavily, and who had high fasting blood glucose levels had an impaired body clock $[9,10]$. However, the present study found that even elderly people can still possibly improve their disturbed clock function depending on the environment. Through light, proper nutrition that ensures quality and quantity, timing of eating, and dynamic interaction between them, hepatocyte function can be remarkably improved. Our subjects were geriatric patients at a care-mix hospital, where a systematic care program for meals, rehabilitation, and bathing was performed along the time axis throughout the day.

Light/dark cycle and mealtimes are related to body clock rhythm. Given that our subjects were treated at the care-mix hospital where these time frames were fixed, meal timing may be involved in Alb synthesis.

To investigate why the subjects' feeding behavior was emphasized more at lunch than at dinner, we analyzed the menu contents. At lunch, noodle dishes were preferred because of 
palatability, and a special menu called "event food", which had more nutrition quantity than the usual one, was occasionally provided. These menu choices were unavailable at dinner. Therefore, emphasizing more on the feeding behavior at lunch than on any daily eating behavior would be better.

Chrononutrition has shown that the regulation of biological clock, which forms a rhythm of approximately $24 \mathrm{~h}$ in a day, is important in health maintenance.

In the biological clock, a group of genes called clock genes regulates the expression of various genes rhythmically, mainly at the transcription level. The central nervous system and the cells of peripheral tissues such as liver tissues are involved in the biological clock. The liver is the body's central organ of metabolism. The expression of many genes in the liver exhibits a circadian rhythm and allows for metabolism regulation [11-15]. Furthermore, light is an important factor that resets (synchronizes) the fine misalignment of biological clocks among cells; however, food intake can be a stronger factor than light [16].

Under the nighttime light, the body clock, especially the peripheral clock, can be disrupted by physical activities and late-night supper ingestion. Disorders in peripheral clocks such as the liver and adipose tissues would cause disruption in the homeostasis of glucose and lipid metabolism, causing lifestyle-related diseases, such as obesity and type 2 diabetes [17-20]. The appropriate biological clock can be achieved by considering not only the content and quantity of meals and nutrition but also meal time; thus, meal timing is important.

Liver clock can be normalized by breakfast but disrupted by late-night supper. Despite the same high-carbohydrate diet is consumed at breakfast and at dinner, the two meals obtained different pathways related to glycolysis and the TCA cycle, which determine glucose metabolism [21-23]. It appears that normalization of liver clock improves Alb metabolism in the liver.

In terms of clinical significance, $\mathrm{Alb}$ is indeed important as a nutritional assessment index for geriatric patients. Alb can be easily measured in clinical settings; hence, it is used as one of the indices to assess the nutritional status of the whole body. When blood Alb concentration decreases, liver disorders caused by undernutrition or decreased liver synthesis, and nephrotic syndrome with renal Alb loss, are considered [24]. Decreased blood Alb level is also a risk factor for diseases that affect lifespan prognosis, such as ischemic heart disease and cerebral infarction [25]. Therefore, when a low serum Alb level is combined with sarcopenia in the elderly, the risk of incidental disorders such as falls also increases, indicating another health issue [26].

Once hypoalbuminemia occurs, the risk of sarcopenia aggravation increases, and the compensatory loss of muscle proteins with decreased protein synthesis also worsens. Therefore, Alb improvement should be prioritized, especially in the elderly. In clinical nutrition, intake of high-quality proteins with a high protein score is recommended for patients with low Alb levels and inadequate protein intake. Induction of body protein synthesis and improvement of the NPC/N ratio, which is the energy/protein balance, are crucial for nutritional support [27]. Our study results suggest "prioritizing lunch in meal timing and prioritizing protein in the nutritional composition ratio of lunch within the permissible range" as an additional recommendation.

\section{Conclusions}

On the basis of the relationship between meal timing and Alb, the following process will be required to positively synthesize Alb in geriatric patients: provision of a menu that ensures the daily required nutritional quantity, prioritizing proteins within the permissible range, and is highly palatable at lunch.

\section{Limitations of the study}

The sample size was small, which included geriatric patients admitted and receiving oral nutritional support at a local smallscale, care-mix hospital in Nada Ward, Kobe City at Hyogo Prefecture. The number of cases was also inadequate. This was a retrospective study, and not a prospective or an interventional one. Therefore, restrictions in the interpretation of results are undeniable. Nevertheless, our results suggested that the concept of chrononutrition should be added to existing nutritional concepts in clinical practice.

\section{Supplementary Material}

Suppl 1. Multiple regression models of geriatric nutrition risk index.

Suppl 2. Multiple regression models of prognostic nutritional index.

Suppl 3. Multiple regression models of controlling nutrition status.

Suppl 4. Relationship between the scores of the second principal component and each nutrition index.

\section{Acknowledgments}

We extend our sincerest gratitude to the patients hospitalized at the Medical Corporation Nakai Hospital who consented to participate in this study. We also acknowledge our special thanks to the medical staff, Ms. Mina Kohara (former registered dietitian) and Ms. Mikako Ochi (current registered dietitian) for supporting the research operations.

\section{Financial Disclosure}

None to declare.

\section{Conflict of Interest}

The authors have no conflict of interest to declare. 


\section{Informed Consent}

The contents of the study were explained to the subjects in advance, and written informed consents were obtained.

\section{Author Contributions}

YF drew up the research plan, dealt with matters regarding ethical research screening, provided detailed explanation of the research to the subjects, collected/analyzed data, and prepared the initial draft. RK, NY, TI, AN, MT, SY, and SN collected the data. HN supervised the interpretation of data and drafting this paper. MN drew up the research plan and matters regarding ethical research screening. MN also explained the research to the subjects and obtained their consent. All authors agree to the submission of this paper.

\section{Data Availability}

The authors declare that the data supporting the findings of this study are available within the article.

\section{References}

1. Tahara Y, Shibata S. Chronobiology and nutrition. Neuroscience. 2013;253:78-88.

2. Andrassy RJ, Durr ED. Albumin: use in nutrition and support. Nutr Clin Pract. 1988;3(6):226-229.

3. Jabbour J, Abou Ali AN, Rabeh W, Al-Shaar L, Avgerinos ED, Habib RH. Role of nutritional indices in predicting outcomes of vascular surgery. J Vasc Surg. 2019;70(2):569-579 e564.

4. Fukuda Y, Kohara M, Hatakeyama A, Ochi M, Nakai M. Influence of geriatric patients' food preferences on the selection of discharge destination. J Clin Med Res. 2020;12(11):705-710.

5. Charlson ME, Pompei P, Ales KL, MacKenzie CR. A new method of classifying prognostic comorbidity in longitudinal studies: development and validation. J Chronic Dis. 1987;40(5):373-383.

6. Ministry of Health, Labour and Welfare. The law regarding the creation of relevant laws to ensure the comprehensive promotion of community-based medical and nursing care. 2014 Law No.83.

7. Takahashi M, Ozaki M, Kang MI, Sasaki H, Fukazawa M, Iwakami T, Lim PJ, et al. Effects of meal timing on postprandial glucose metabolism and blood metabolites in healthy adults. Nutrients. 2018;10(11):1763.

8. Ley RE, Turnbaugh PJ, Klein S, Gordon JI. Microbial ecology: human gut microbes associated with obesity. Nature. 2006;444(7122):1022-1023.

9. Ando H, Ushijima K, Kumazaki M, Takamura T, Yokota $\mathrm{N}$, Saito T, Irie S, et al. Influence of age on clock gene expression in peripheral blood cells of healthy women. J Gerontol A Biol Sci Med Sci. 2010;65(1):9-13.
10. Ando H, Ushijima K, Kumazaki M, Eto T, Takamura T, Irie $\mathrm{S}$, Kaneko $\mathrm{S}$, et al. Associations of metabolic parameters and ethanol consumption with messenger RNA expression of clock genes in healthy men. Chronobiol Int. 2010;27(1):194-203.

11. Okamura H. Clock genes in cell clocks: roles, actions, and mysteries. J Biol Rhythms. 2004;19(5):388-399.

12. Asher G, Schibler U. Crosstalk between components of circadian and metabolic cycles in mammals. Cell Metab. 2011;13(2):125-137.

13. Eckel-Mahan K, Sassone-Corsi P. Metabolism and the circadian clock converge. Physiol Rev. 2013;93(1):107135.

14. Asher G, Sassone-Corsi P. Time for food: the intimate interplay between nutrition, metabolism, and the circadian clock. Cell. 2015;161(1):84-92.

15. Panda S. Circadian physiology of metabolism. Science. 2016;354(6315):1008-1015.

16. Manoogian ENC, Panda S. Circadian rhythms, timerestricted feeding, and healthy aging. Ageing Res Rev. 2017;39:59-67.

17. Forrestel AC, Miedlich SU, Yurcheshen M, Wittlin SD, Sellix MT. Chronomedicine and type 2 diabetes: shining some light on melatonin. Diabetologia. 2017;60(5):808822.

18. Qian J, Scheer F. Circadian System and Glucose Metabolism: Implications for Physiology and Disease. Trends Endocrinol Metab. 2016;27(5):282-293.

19. Jamshed H, Beyl RA, Della Manna DL, Yang ES, Ravussin E, Peterson CM. Early time-restricted feeding improves 24-hour glucose levels and affects markers of the circadian clock, aging, and autophagy in humans. Nutrients. 2019;11(6):1234.

20. Sookoian S, Gemma C, Gianotti TF, Burgueno A, Castano G, Pirola CJ. Genetic variants of Clock transcription factor are associated with individual susceptibility to obesity. Am J Clin Nutr. 2008;87(6):1606-1615.

21. Giskeodegard GF, Davies SK, Revell VL, Keun H, Skene DJ. Diurnal rhythms in the human urine metabolome during sleep and total sleep deprivation. Sci Rep. 2015;5:14843.

22. Davies SK, Ang JE, Revell VL, Holmes B, Mann A, Robertson FP, Cui N, et al. Effect of sleep deprivation on the human metabolome. Proc Natl Acad Sci U S A. 2014;111(29):10761-10766.

23. Dallmann R, Viola AU, Tarokh L, Cajochen C, Brown SA. The human circadian metabolome. Proc Natl Acad Sci U S A. 2012;109(7):2625-2629.

24. Sonia C, Daniel C, Fernando GB, Inaki AA, Fernando MC, Vincenzo M. Serum albumin and health in older people: Review and metaanalysis. Maturitas. 2015;81(1):17-27.

25. Gonzalez-Pacheco H, Amezcua-Guerra LM, Sandoval J, Martinez-Sanchez C, Ortiz-Leon XA, Pena-Cabral MA, Bojalil R. Prognostic implications of serum albumin levels in patients with acute coronary syndromes. Am J Cardiol. 2017;119(7):951-958.

26. Uemura K, Doi T, Lee S, Shimada H. Sarcopenia and low serum albumin level synergistically increase the risk of 
incident disability in older adults. J Am Med Dir Assoc. 2019;20(1):90-93.

27. Amagai T, Hasegawa M, Kitagawa M, Haji S. Non-Pro- tein calorie: Nitrogen ratio $(\mathrm{NPC} / \mathrm{N})$ as an indicator of nitrogen balance in clinical settings. Biomed J Sci \& Tech Res. 2018;6(1):5013-5015. 